\title{
High-flow nasal oxygen therapy and noninvasive ventilation in the management of acute hypoxemic respiratory failure
}

\author{
Jean-Pierre Frat ${ }^{1,2,3}$, Rémi Coudroy ${ }^{1,2,3}$, Nicolas Marjanovic ${ }^{2,3,4}$, Arnaud W. Thille ${ }^{1,2,3}$ \\ ${ }^{1}$ CHU de Poitiers, Réanimation Médicale, Poitiers, France; ${ }^{2}$ INSERM, CIC-1402, équipe 5 ALIVE, Poitiers, France; ${ }^{3}$ Université de Poitiers, Faculté \\ de Médecine et de Pharmacie de Poitiers, Poitiers, France; ${ }^{4} \mathrm{CHU}$ de Poitiers, Services des Urgences, Poitiers, France \\ Contributions: (I) Conception and design: JP Frat; (II) Administrative support: None; (III) Provision of study materials or patients: All authors; (IV) \\ Collection and assembly of data: All authors; (V) Data analysis and interpretation: All authors; (VI) Manuscript writing: All authors; (VII) Final \\ approval of manuscript: All authors. \\ Correspondence to: Jean-Pierre Frat. CHU de Poitiers, Service de Réanimation Médicale, 2, rue de la Milétrie, CS 90577, 86021 POITIERS cedex, \\ France. Email: jean-pierre.frat@chu-poitiers.fr.
}

\begin{abstract}
High-flow nasal cannula (HFNC) oxygen therapy is a recent technique delivering a high flow of heated and humidified gas. HFNC is simpler to use and apply than noninvasive ventilation (NIV) and appears to be a good alternative treatment for hypoxemic acute respiratory failure (ARF). HFNC is better tolerated than NIV, delivers high fraction of inspired oxygen $\left(\mathrm{FiO}_{2}\right)$, generates a low level of positive pressure and provides washout of dead space in the upper airways, thereby improving mechanical pulmonary properties and unloading inspiratory muscles during ARF. A recent multicenter randomized controlled trial showed benefits of HFNC concerning mortality and intubation in severe patients with hypoxemic ARF. In management of patients with hypoxemic ARF, NIV results have been conflicting. Despite improved oxygenation, NIV delivered with face mask may generate high tidal volumes and subsequent ventilatorinduced lung injury. An approach applying NIV with a helmet, high levels of positive end-expiratory pressure (PEEP) and low pressure support (PS) levels seems to open new opportunities in patients with hypoxemic ARF. However, a large-scale randomized controlled study is needed to assess and compare this approach with HFNC.
\end{abstract}

Keywords: High-flow oxygen therapy; noninvasive ventilation (NIV); acute respiratory failure (ARF)

Submitted May 04, 2017. Accepted for publication Jun 01, 2017.

doi: 10.21037/atm.2017.06.52

View this article at: http://dx.doi.org/10.21037/atm.2017.06.52

\section{Introduction}

Oxygen therapy delivered via face mask with reservoir bag is usually the first-line treatment in acute respiratory failure (ARF). However, this strategy has many limits and fails to provide ventilatory support. The fraction of inspired oxygen $\left(\mathrm{FiO}_{2}\right)$ delivered is limited and comfort is compromised by dry gas, which also impairs mucociliary clearance.

Since the 90's, noninvasive ventilation (NIV) has been largely used with strong level of evidence in cardiogenic pulmonary edema and chronic obstructive pulmonary disease (COPD) exacerbation but with controversial results in ARF. NIV improves gas exchange and reduces inspiratory effort through positive pressure. However, good tolerance to NIV is sometimes difficult to achieve due to frequent leaks around the mask, possibly leading to patient-ventilator asynchrony and even to intubation. It may have other deleterious effects such as delayed intubation by masking signs of respiratory distress, or barotrauma by the high tidal volume potentially generated under positive pressure.

High-flow nasal cannulae oxygen therapy (HFNC) is currently spreading in adult intensive care unit (ICU) after first being used in pre-term neonates and pediatric care, as a first-line treatment for respiratory distress syndrome, and apnea of prematurity. More recently, physiological, pilot studies and controlled trials have drawn attention 
to HFNC's potential role in adults. HFNC is a strategy providing good comfort through warmed and humidified gas flow delivered via nasal prongs. It preserves high $\mathrm{FiO}_{2}$ and generates a low level of positive pressure in the upper airways due to a high flow of gas, which also provides washout of dead space in the upper airways. In this review we will focus on HFNC's physiological effects, provide clinical evidence during $\mathrm{ARF}$ and discuss its differences with NIV.

\section{Pathophysiologic rationale for NIV and HFNC oxygen therapy in hypoxemic ARF}

Hypoxemic ARF is characterized by severe acute hypoxemia $\left(\mathrm{PaO}_{2} / \mathrm{FiO}_{2}\right.$ ratio $\left.<300\right)$ and causes a high respiratory drive reflected by clinical signs of respiratory distress. This drive results in highly labored breathing, especially during inspiration. The blood gas pattern is hallmarked by hyperventilation and hypocapnia. Consequently, occurrence of hypercapnia is a sign of impending respiratory muscle fatigue that must be considered as a serious complication. Thus a rationale for oxygenation supports should consequently combine symptomatic treatment of hypoxemia and support of the high load imposed on the respiratory muscles. Oxygenation strategies must nonetheless not delay intubation by masking signs of life-threatening respiratory failure $(1,2)$ or worsen pre-existing lung insults (3-5).

\section{Technical characteristics of NIV and HFNC}

The main hallmark of NIV is its assistance of the spontaneous activity of the respiratory system by administration of positive pressure into the lungs through an external interface, i.e., a commonly used face mask connected to a humidification system, a heated humidifier or a heat and moisture exchanger, and a ventilator. The most commonly used mode combines pressure support (PS) ventilation plus positive end-expiratory pressure (PEEP) (6), or simply apply continuous positive airway pressure (CPAP) (7). HFNC oxygen therapy is a simple system initially consisting in an air-oxygen blender directly connected to a flow meter (set up to $70 \mathrm{~L} / \mathrm{min}$ ) or in a turbine connected to an oxygen flow meter. The gas mixture containing up to $100 \%$ of oxygen is routed to a heated humidifier delivering gas conditioned at $37^{\circ} \mathrm{C}$ and completely saturated with water (relative humidity: $100 \%$ ). Gases are delivered to the patient via a simple interface, nasal prongs or cannulae, which are configured to provide high flow and limit water condensation (8). Currently, most ICU ventilators offer an option enabling high-flow oxygen therapy, but they need to be connected to the heated humidifier and circuit described above. The constant flow rate of gas in the HFNC system generates variable pressures in airways according to the patient's breath effort and dynamic thoracic compliance, contrary to NIV, which adapts gas flow rate to maintain a preset constant inspiratory PS and PEEP. Consequently physiological effects with the two systems differ.

\section{Oxygenation and PEEP effect}

The peak inspiratory flow generated by patients with ARF is a mean $30-40 \mathrm{~L} / \mathrm{min}$, and can exceed 60 and even reach $120 \mathrm{~L} / \mathrm{min}$ in more severe patients (9), which is substantially higher than the flow rates of standard oxygen delivery systems. As a result, inhaled oxygen is mixed with room air, thereby reducing the $\mathrm{FiO}_{2}$ delivered to the patient, which does not exceed 0.7 with standard oxygen systems $(10,11)$.

The $\mathrm{FiO}_{2}$ delivered to the patient using NIV can reach $100 \%$ without leaks. The other determinant of oxygenation is the PEEP, which is also limited by the leakage created by high pressure in the mask. L'Her et al. have successively described the physiological effects of standard oxygen, CPAP or NIV in 10 patients treated for hypoxemic ARF (12). CPAP improved gas exchange with an increased $\mathrm{PaO}_{2} / \mathrm{FiO}_{2}$ ratio as compared to standard oxygen; the higher the PEEP, up to $10 \mathrm{cmH}_{2} \mathrm{O}$, the higher $\mathrm{PaO}_{2} /$ $\mathrm{FiO}_{2}$ ratio, whereas PS level had no direct effect on oxygenation (12). In an observational study including 64 patients with ARF, the level of $\mathrm{PaO}_{2} / \mathrm{FiO}_{2}$ ratio improvement under NIV was comparable with invasive ventilation, with the same level of PEEP (around $5 \mathrm{cmH}_{2} \mathrm{O}$ ) after initial treatment with standard oxygen (13).

HFNC can deliver high $\mathrm{FiO}_{2}$ compared to other oxygen delivery systems, through a higher flow rate, up to $70 \mathrm{~L} / \mathrm{min}$, which in most cases exceeds the patient peak inspiratory flow rate (Figure 1). In a physiological study, Sim et al. evaluated performance of oxygen delivery devices in healthy subjects by measuring $\mathrm{FiO}_{2}$ using a standard mask, a non-rebreathing mask and HFNC (11). With a standard mask, $\mathrm{FiO}_{2}$ was less than 0.6 despite a flow of 12 $\mathrm{L} / \mathrm{min}$, and dropped below 0.5 when ARF was simulated by thoracic contention. Although the non-rebreathing mask avoided such a $\mathrm{FiO}_{2}$ drop during simulated ARF, the highest $\mathrm{FiO}_{2}$ obtained was less than 0.7 , even with a flow rate of $15 \mathrm{~L} / \mathrm{min}$. By comparison, $\mathrm{FiO}_{2}$ reached 0.85 using HFNC 


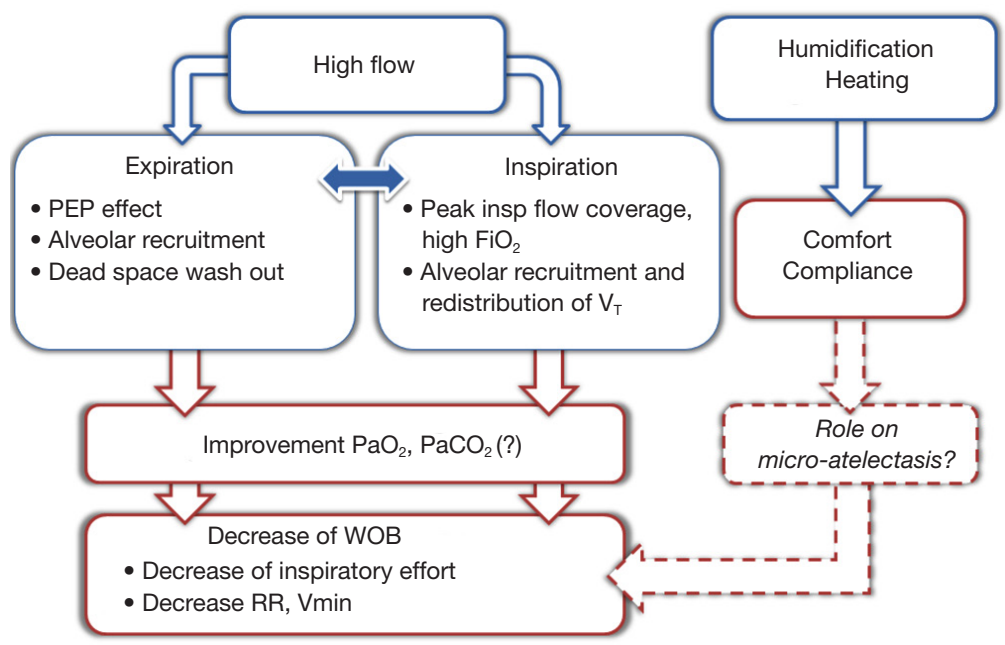

Figure 1 Physiological effects of HFNC oxygen therapy. HFNC, high-flow nasal cannula.

set with a flow rate of $40 \mathrm{~L} / \mathrm{min}$ (11). Nonetheless, HFNC is likely to perform better during ARF than traditional oxygen supplementation with high $\mathrm{FiO}_{2}$ more reliably delivered. Indeed, HFNC may also generate a low level of positive pressure in the upper airway directly proportional to the gas flow delivered, thereby possibly improving oxygenation. However, due to air leakage the pressure levels are quite variable. The large nasal prongs could create some nasal obstruction, while continuously delivered high flow causes resistance during expiration, thereby generating positive pressure. Consequently, positive pressure is markedly reduced when the patient opens his mouth. Parke et al. measured nasopharyngeal pressure in postoperative patients at different levels of flow using HFNC (14). The pressure recorded during spontaneous breathing on HFNC correlated linearly with administered flow-rate and was significantly higher when subjects breathed with their mouths closed: exceeding $3 \mathrm{cmH}_{2} \mathrm{O}$ with a gas flow rate of $50 \mathrm{~L} / \mathrm{min}$ with mouth closed, and less than $2 \mathrm{cmH}_{2} \mathrm{O}$ with mouth open (14). This low positive airway pressure generates a PEEP effect including alveolar recruitment that might also improve gas exchange (Figure 1). In a physiological study measuring pulmonary volumes after cardiac surgery using electrical impedance tomography (EIT), increased end-expiratory lung volume was found with HFNC, suggesting alveolar recruitment induced by PEEP effect (15). In ARF, Mauri et al. found that during inspiration tidal volume did not change under HFNC after starting with standard oxygen, suggesting homogeneous distribution of tidal volume, i.e., better distribution of lung densities, suggesting less regional lung strain with HFNC (16).

However, clinical studies have shown less improvement in oxygenation with HFNC than with NIV, probably due to lower impact of the PEEP effect with HFNC than with NIV $(10,17)$. In a pilot study successively assessing standard oxygen, HFNC and NIV in patients with ARF, $\mathrm{PaO}_{2}$ increased from standard oxygen to HFNC without changes in $\mathrm{PaO}_{2} / \mathrm{FiO}_{2}$ ratio (17). This suggests that oxygenation improvement was mainly due to increased $\mathrm{FiO}_{2}$. By contrast, $\mathrm{PaO}_{2}$ further increased with NIV with a significant increase in $\mathrm{PaO}_{2} / \mathrm{FiO}_{2}$ ratio reflecting probable alveolar recruitment induced by PEEP. These results were confirmed in a large multicenter study comparing standard oxygen, HFNC and NIV (10).

\section{Ventilatory support}

Respiratory muscle activity in hypoxemic ARF is especially high due to high respiratory drive. In this situation, spontaneous breathing may be deleterious, aggravating lung injury through changes in global or regional pressure, even without any ventilatory support (18-20). Brochard et al. consequently developed the concept of patient self-inflicted lung injury (P-SILI) (19). Hence, oxygenation strategies are aimed at unloading inspiratory muscles while preserving superimposed lung injuries, in addition to improve oxygenation.

The PS delivered under NIV during inspiration is one of the determinants of the tidal volume generated 
by the patient, depending on breath effort and thoracic compliance. Resulting minute ventilation is thus determined by patient-triggered breaths and preset levels of PS above PEEP. Despite the beneficial effect of PEEP in oxygenation, it does not unload respiratory muscles. In the physiological study by L'Her et al., inspiratory work of breathing decreased significantly when PS was applied above PEEP, as compared to CPAP (PEEP alone) or standard oxygen (12). However, combined PS and PEEP, which may improve oxygenation and unload respiratory muscles, has a potential deleterious effect. Overly high ventilator assistance can lead to high tidal volumes and compromise lung protection $(3,4,21)$. A recent cohort study showed the difficulty of maintaining tidal volumes between 6 to $8 \mathrm{~mL} / \mathrm{kg}$ of predicted body weight by manipulating PS level on top of low PEEP (3).

Two studies specifically assessed the physiological effects of HFNC in patients with ARF treated first by standard oxygen through a non-rebreathing mask, HFNC and CPAP $(16,22)$. Vargas et al. showed a decrease in work of breathing under HFNC, assessed by the variation of esophageal pressure (diminution of pressure time produced during inspiration), of the same magnitude as with CPAP (22). Mauri et al. assumed that better working conditions could be partially due to improvement inspiratory effort and pulmonary compliance (16). They observed decreased peak expiratory flow assessed by EIT, potentially reflecting improvement of dynamic lung compliance under HFNC compared to standard oxygen. Otherwise, the high-flow rate of gas continuously delivered may flush upper airways, generating a washout of dead space and then flushing carbon dioxide out $(23,24)$. This effect associated with mechanically improved of thoracic properties results in reduced inspiratory effort and minute ventilation requirement (Figure 1). This is consistent with the common finding of decreased respiratory rate and work of breathing with HFNC $(16,22)$.

\section{Comfort and bumidification}

The success of non-invasive strategies also depends on tolerance and patient compliance. Indeed, intolerance to NIV can affect $20-25 \%$ (25) of patients treated for hypoxemic ARF and lead to intubation in around 10\% (26). Humidification delivered during NIV may vary from 5 to $30 \mathrm{mg} / \mathrm{L}$ depending on presence or type of humidification systems. In healthy subjects, low levels of humidification under CPAP or absence of any additional humidification system of under NIV were associated with less comfort (27). Other authors reported that low levels of humidification during a long period of NIV, i.e., 12 and 24 hours, was associated with less comfort and higher oral dryness feeling (28). However, whether heating and humidification of inspired gas may prevent thick secretions, potential dysfunction of mucociliary clearance, atelectasis facilitation and clinical impact is currently unproven (29).

Despite a high oxygen flow rate, HFNC seems to be better tolerated than NIV and standard oxygen. The heated humidifier of HFNC provides the same physiological conditions as those found in alveoli with absolute humidity of $44 \mathrm{mg} / \mathrm{L}$ of water (8). Standard oxygen through face mask provides non-humidified or under-humidified cold gas that dries the upper airway and leads to reduced patient comfort, even when a bubble humidifier is used (30). Most studies have reported better comfort and dyspnea feeling with HFNC than with standard oxygen through a mask or NIV $(10,17,31-33)$ with subsequently improved compliance (34).

\section{Clinical impact of HFNC oxygen therapy and NIV in hypoxemic ARF}

Although the use of NIV for ARF has been progressively increasing for two decades, HFNC can be considered as an alternative, given its physiological effects in hypoxemic ARF patients for whom NIV indications remain controversial.

\section{Hypoxemic ARF}

To date, few randomized controlled studies have found better outcomes with NIV than with standard oxygen $(35,36)$. The heterogeneity of patients included in studies comparing NIV to standard oxygen, i.e., patients with hypercapnia or cardiogenic pulmonary edema, may explain high intubation rate variability (7,35-38). More recently, cohort studies including patients treated with NIV for hypoxemic ARF reported a high intubation rate, potentially exceeding $50 \%$ (39). Similarly poor outcomes have been observed in cohort studies of ARDS patients treated with NIV $(40,41)$, who represented a majority (almost 70\%) of patients with hypoxemic ARF (26,39). Another limitation for NIV in hypoxemic ARF is the high mortality rate $(50 \%)$ in case of NIV failure $(1,39)$. In the recent large-scale international LUNG SAFE study, severe hypoxemic patients who failed NIV had a higher mortality rate (approximately $43 \%$ ) than invasively ventilated 
patients (42). Indeed, many authors have argued that the usual beneficial effect of NIV on oxygenation and dyspnea could hide an underlying worsening potentially resulting in life-threatening respiratory failure in case of NIV interruption (1). However, establishment of pre-specified intubation criteria to avoid delayed intubation does not seem sufficient to improve patient prognosis in case of NIV failure. In their cohort study of patients treated with NIV for hypoxemic ARF, Thille et al. reported no difference in delay of intubation between patients who survived or not after NIV failure (39). Consequently, a randomized controlled trial (Florali study) was conducted by Frat et al. to compare three strategies of oxygenation: standard oxygen, HFNC and NIV (10). This study included 310 non-hypercapnic patients with hypoxemic ARF $\left(\mathrm{PaO}_{2} / \mathrm{FiO}_{2}\right.$ $<300 \mathrm{mmHg}$ ) (10). Although the intubation rate among the three groups was not significantly different, 90-day mortality was lower in patients treated by HFNC: $12 \%$ with HFNC vs. $23 \%$ with standard oxygen and $28 \%$ with $\mathrm{NIV}, \mathrm{P}=0.02$. This may have been caused by a significant lower intubation rate in the subgroup of severe hypoxemic patients $\left(\mathrm{PaO}_{2} / \mathrm{FiO}_{2}<200\right)$ treated by HFNC than by the two other treatments: $35 \%, 53 \%$ and $58 \%$, respectively, $\mathrm{P}=0.009$ (10).

Two points from this study call for highlighting. First, the patients treated with NIV received HFNC between NIV sessions and their mortality was significantly higher than in patients treated with HFNC alone. Second, time to intubation was not significantly different between the three groups (10), suggesting that the poor outcomes observed in this study could be due mainly to the oxygenation strategy applied and not to delayed intubation. A possible assumption is that high tidal volumes $(9.2 \pm 3.0 \mathrm{~mL} / \mathrm{kg}$ in mean) might further worsen a pre-existing lung insult by inducing superimposed ventilator-induced lung injury, thereby leading to intubation (3). Consequently, the way of applying NIV (continuously or not) and the settings (PS and PEEP), should be questioned as it may impact outcomes. The final PS level and PEEP were $8 \pm 3$ and $5 \pm 1 \mathrm{cmH}_{2} \mathrm{O}$ respectively in the Florali study (10), which were similar to those in previous studies: PS between 9 to $11 \mathrm{cmH}_{2} \mathrm{O}$ and PEEP 4 to $7 \mathrm{cmH}_{2} \mathrm{O}(26,35-38,43)$, while NIV was continuously delivered except in the study by Hilbert et al. (43). Moreover, we observed that patients with poor outcomes were more likely to generate large tidal volumes at NIV initiation than those who did not $(4,5)$, even though PS levels did not differ (data in submission). Though the risk of ventilator-induced lung injury has not been proven, the large tidal volumes favored by NIV do not ensure lung protection (21) and might heighten the intubation rate among patients treated with NIV (3). Moreover, PEEP levels were low even though many patients had potential ARDS, as $79 \%$ of them had bilateral pulmonary infiltrates (10).

In a randomized controlled study including 83 ARDS patients Patel et al. reported the benefits of NIV delivered through a helmet, thereby opening new perspectives on use of NIV in patients with hypoxemic ARF (44). Indeed, the rate of NIV failure was higher in patients treated with face mask than in those treated with helmet (18\% and 61\% respectively, $\mathrm{P}<0.01)$ (44). Besides different interfaces, settings were dramatically different between groups with lower levels of PS and higher PEEP in the helmet group, potentially favoring more alveolar recruitment and lung protection. Mortality rate was lower in the helmet group, but reached $34 \%$ at day 90 , higher than the mortality reported in NIV-treated patients in the Florali study (10).

\section{Immunocompromised patients}

In the early 2000s, two small studies reported benefits of NIV compared to standard oxygen in the subset of immunocompromised patients with ARF, as intubation and mortality rates were reduced $(43,45)$. However, probably due to advances in diagnostic and therapeutic options, survival of immunocompromised patients has improved in recent years likely (46). Recently, a large randomized controlled trial found no difference in terms of intubation or mortality between patients treated with NIV and with oxygen alone (47). In this study, nearly $40 \%$ of them received HFNC, and mortality rate did not differ between the patients treated with HFNC alone and those treated with NIV and HFNC between NIV sessions (32\% with HFNC alone $v s .25 \%$ with NIV and HFNC).

Conversely, in a post-hoc analysis including 82 immunocompromised patients, those treated with HFNC alone had a lower intubation rate than the others $(31 \%$ with HFNC vs. $43 \%$ with standard oxygen and $65 \%$ with NIV, $\mathrm{P}=0.04$ ) (5). Similarly, the mortality rate at day 90 was lower with HFNC than with standard oxygen or NIV ( $15 \%$ vs. $27 \%$ and $46 \%$, respectively, $\mathrm{P}=0.046$ ). Similar results were reported in a retrospective cohort including 115 immunocompromised patients with $\mathrm{ARF}$ treated with HFNC or NIV: intubation rate $35 \%$ vs. $55 \%, \mathrm{P}=0.04$ and mortality rate $20 \%$ vs. $40 \%, \mathrm{P}=0.02$, respectively for HFNC and NIV. Thus, although its efficacy has not yet 
been conclusively proven, HFNC could improve outcomes of immunocompromised patients admitted to ICU for ARF. Two large-scale randomized trials comparing HFNC to NIV or standard oxygen in this subset of patients with hypoxemic ARF are ongoing (NCT02978300; NCT02739451).

\section{Conclusions}

HFNC seems to be a good alternative to standard oxygen and NIV as treatment for patients with hypoxemic ARF. Its good tolerance, physiological effects including high $\mathrm{FiO}_{2}$, PEEP effect and dead space washout lead to decreased work of breathing and probably avoid lung strain. A recent multicenter randomized controlled trial showed benefits of HFNC as regards mortality and intubation in severe patients with hypoxemic ARF. Uncertainty remains about benefits of NIV in management of patients with hypoxemic ARF. Despite improvement in oxygenation, NIV delivered with face mask may generate high tidal volumes and subsequent ventilator-induced lung injury. However, an approach applying NIV with a helmet, high levels of PEEP and low levels of PS might be less harmful; a large-scale randomized controlled study is needed to compare NIV delivered through face mask or helmet with HFNC.

\section{Acknowledgements}

We want to thank Jeffrey Arsham for reviewing and editing the manuscript.

\section{Footnote}

Conflicts of Interest: JPF has conflicts of interest with the firm Fisher \& Paykel, which provides equipment for studies and personnal fees for lectures. The other authors have no conflicts of interest to declare.

\section{References}

1. Carrillo A, Gonzalez-Diaz G, Ferrer M, et al. Noninvasive ventilation in community-acquired pneumonia and severe acute respiratory failure. Intensive Care Med 2012;38:458-66.

2. Kang BJ, Koh Y, Lim CM, et al. Failure of high-flow nasal cannula therapy may delay intubation and increase mortality. Intensive Care Med 2015;41:623-32.

3. Carteaux G, Millan-Guilarte T, De Prost N, et al. Failure of Noninvasive Ventilation for De Novo Acute Hypoxemic Respiratory Failure: Role of Tidal Volume. Crit Care Med 2016;44:282-90.

4. Frat JP, Ragot S, Coudroy R, et al. Tidal volume and noninvasive ventilation failure-Authors' reply. Lancet Respir Med 2016;4:e52.

5. Frat JP, Ragot S, Girault C, et al. Effect of non-invasive oxygenation strategies in immunocompromised patients with severe acute respiratory failure: a post-hoc analysis of a randomised trial. Lancet Respir Med 2016;4:646-52.

6. Demoule A, Chevret S, Carlucci A, et al. Changing use of noninvasive ventilation in critically ill patients: trends over 15 years in francophone countries. Intensive Care Med 2016;42:82-92.

7. Delclaux C, L'Her E, Alberti C, et al. Treatment of acute hypoxemic nonhypercapnic respiratory insufficiency with continuous positive airway pressure delivered by a face mask: A randomized controlled trial. JAMA 2000;284:2352-60.

8. Frat JP, Goudet V, Girault C. High flow, humidifiedreheated oxygen therapy: a new oxygenation technique for adults. Rev Mal Respir 2013;30:627-43.

9. Katz JA, Marks JD. Inspiratory work with and without continuous positive airway pressure in patients with acute respiratory failure. Anesthesiology 1985;63:598-607.

10. Frat JP, Thille AW, Mercat A, et al. High-flow oxygen through nasal cannula in acute hypoxemic respiratory failure. N Engl J Med 2015;372:2185-96.

11. Sim MA, Dean P, Kinsella J, et al. Performance of oxygen delivery devices when the breathing pattern of respiratory failure is simulated. Anaesthesia 2008;63:938-40.

12. L'Her E, Deye N, Lellouche F, et al. Physiologic effects of noninvasive ventilation during acute lung injury. Am J Respir Crit Care Med 2005;172:1112-8.

13. Antonelli M, Conti G, Rocco M, et al. A comparison of noninvasive positive-pressure ventilation and conventional mechanical ventilation in patients with acute respiratory failure. N Engl J Med 1998;339:429-35.

14. Parke RL, Eccleston ML, McGuinness SP. The effects of flow on airway pressure during nasal high-flow oxygen therapy. Respir Care 2011;56:1151-5.

15. Corley A, Caruana LR, Barnett AG, et al. Oxygen delivery through high-flow nasal cannulae increase end-expiratory lung volume and reduce respiratory rate in post-cardiac surgical patients. Br J Anaesth 2011;107:998-1004.

16. Mauri T, Turrini C, Eronia N, et al. Physiologic Effects of High-Flow Nasal Cannula in Acute Hypoxemic 
Respiratory Failure. Am J Respir Crit Care Med 2017;195:1207-15.

17. Frat JP, Brugiere B, Ragot S, et al. Sequential application of oxygen therapy via high-flow nasal cannula and noninvasive ventilation in acute respiratory failure: an observational pilot study. Respir Care 2015;60:170-8.

18. Brochard L. Ventilation-induced lung injury exists in spontaneously breathing patients with acute respiratory failure: Yes. Intensive Care Med 2017;43:250-2.

19. Brochard L, Slutsky A, Pesenti A. Mechanical Ventilation to Minimize Progression of Lung Injury in Acute Respiratory Failure. Am J Respir Crit Care Med 2017;195:438-42.

20. Yoshida T, Uchiyama A, Matsuura N, et al. Spontaneous breathing during lung-protective ventilation in an experimental acute lung injury model: high transpulmonary pressure associated with strong spontaneous breathing effort may worsen lung injury. Crit Care Med 2012;40:1578-85.

21. Slutsky AS, Ranieri VM. Ventilator-induced lung injury. N Engl J Med 2014;370:980.

22. Vargas F, Saint-Leger M, Boyer A, et al. Physiologic Effects of High-Flow Nasal Cannula Oxygen in Critical Care Subjects. Respir Care 2015;60:1369-76.

23. Möller W, Celik G, Feng S, et al. Nasal high flow clears anatomical dead space in upper airway models. J Appl Physiol (1985) 2015;118:1525-32.

24. Moller W, Feng S, Domanski U, et al. Nasal high flow reduces dead space. J Appl Physiol (1985) 2017;122:191-7.

25. Demoule A, Girou E, Richard JC, et al. Benefits and risks of success or failure of noninvasive ventilation. Intensive Care Med 2006;32:1756-65.

26. Antonelli M, Conti G, Moro ML, et al. Predictors of failure of noninvasive positive pressure ventilation in patients with acute hypoxemic respiratory failure: a multicenter study. Intensive Care Med 2001;27:1718-28.

27. Lellouche F, Maggiore SM, Lyazidi A, et al. Water content of delivered gases during non-invasive ventilation in healthy subjects. Intensive Care Med 2009;35:987-95.

28. Oto J, Imanaka H, Nishimura M. Clinical factors affecting inspired gas humidification and oral dryness during noninvasive ventilation. J Crit Care 2011;26:535 e9-e15.

29. Williams R, Rankin N, Smith T, et al. Relationship between the humidity and temperature of inspired gas and the function of the airway mucosa. Crit Care Med 1996;24:1920-9.

30. Chanques G, Riboulet F, Molinari N, et al. Comparison of three high flow oxygen therapy delivery devices: a clinical physiological cross-over study. Minerva Anestesiol
2013;79:1344-55.

31. Cuquemelle E, Pham T, Papon JF, et al. Heated and humidified high-flow oxygen therapy reduces discomfort during hypoxemic respiratory failure. Respir Care 2012;57:1571-7.

32. Roca O, Masclans JR. High-flow nasal cannula oxygen therapy: innovative strategies for traditional procedures. Crit Care Med 2015;43:707-8.

33. Sztrymf B, Messika J, Bertrand F, et al. Beneficial effects of humidified high flow nasal oxygen in critical care patients: a prospective pilot study. Intensive Care Med 2011;37:1780-6.

34. Maggiore SM, Idone FA, Vaschetto R, et al. Nasal Highflow vs Venturi Mask Oxygen Therapy After Extubation: Effects on Oxygenation, Comfort and Clinical Outcome. Am J Respir Crit Care Med 2014;190:282-8.

35. Confalonieri M, Potena A, Carbone G, et al. Acute respiratory failure in patients with severe communityacquired pneumonia. A prospective randomized evaluation of noninvasive ventilation. Am J Respir Crit Care Med 1999;160:1585-91.

36. Ferrer M, Esquinas A, Leon $M$, et al. Noninvasive ventilation in severe hypoxemic respiratory failure: a randomized clinical trial. Am J Respir Crit Care Med 2003;168:1438-44.

37. Martin TJ, Hovis JD, Costantino JP, et al. A randomized, prospective evaluation of noninvasive ventilation for acute respiratory failure. Am J Respir Crit Care Med 2000;161:807-13.

38. Wysocki M, Tric L, Wolff MA, et al. Noninvasive pressure support ventilation in patients with acute respiratory failure. A randomized comparison with conventional therapy. Chest 1995;107:761-8.

39. Thille AW, Contou D, Fragnoli C, et al. Non-invasive ventilation for acute hypoxemic respiratory failure: intubation rate and risk factors. Crit Care 2013;17:R269.

40. Antonelli M, Conti G, Esquinas A, et al. A multiplecenter survey on the use in clinical practice of noninvasive ventilation as a first-line intervention for acute respiratory distress syndrome. Crit Care Med 2007;35:18-25.

41. Rana S, Jenad H, Gay PC, et al. Failure of non-invasive ventilation in patients with acute lung injury: observational cohort study. Crit Care 2006;10:R79.

42. Bellani G, Laffey JG, Pham T, et al. Noninvasive Ventilation of Patients with Acute Respiratory Distress Syndrome. Insights from the LUNG SAFE Study. Am J Respir Crit Care Med 2017;195:67-77. 
43. Hilbert G, Gruson D, Vargas F, et al. Noninvasive ventilation in immunosuppressed patients with pulmonary infiltrates, fever, and acute respiratory failure. $\mathrm{N}$ Engl J Med 2001;344:481-7.

44. Patel BK, Wolfe KS, Pohlman AS, et al. Effect of Noninvasive Ventilation Delivered by Helmet vs Face Mask on the Rate of Endotracheal Intubation in Patients With Acute Respiratory Distress Syndrome: A Randomized Clinical Trial. JAMA 2016;315:2435-41.

45. Antonelli M, Conti G, Bufi M, et al. Noninvasive ventilation for treatment of acute respiratory failure in patients undergoing solid organ transplantation: a

Cite this article as: Frat JP, Coudroy R, Marjanovic N, Thille AW. High-flow nasal oxygen therapy and noninvasive ventilation in the management of acute hypoxemic respiratory failure. Ann Transl Med 2017;5(14):297. doi: 10.21037/ atm.2017.06.52 randomized trial. JAMA 2000;283:235-41.

46. Lemiale V, Resche-Rigon M, Mokart D, et al. Acute respiratory failure in patients with hematological malignancies: outcomes according to initial ventilation strategy. A groupe de recherche respiratoire en reanimation onco-hematologique (Grrr-OH) study. Ann Intensive Care 2015;5:28.

47. Lemiale V, Mokart D, Resche-Rigon M, et al. Effect of Noninvasive Ventilation vs Oxygen Therapy on Mortality Among Immunocompromised Patients With Acute Respiratory Failure: A Randomized Clinical Trial. JAMA 2015;314:1711-9. 